\title{
Effect of Temperature on Thekopsora minima Urediniospores and Uredinia
}

\author{
S. E. Pfister, Vermont Agency of Agriculture, Montpelier 05620-2901; and S. Halik and D. R. Bergdahl, School of \\ Environment and Natural Resources, University of Vermont, Burlington 05405
}

\begin{abstract}
Pfister, S. E., Halik, S., and Bergdahl, D. R. 2004. Effect of temperature on Thekopsora minima urediniospores and uredinia. Plant Dis. 88:359-362.

Thekopsora minima is a heteroecious rust, with spermogonia and aecia occurring on the needles of hemlock (Tsuga spp.) and uredinia, telia, and basidia occurring on the leaves of ericaceous genera, including species of Rhododendron. The effect of temperature was determined for urediniospore germination, germ tube growth, and infection efficiency on Rhododendron 'White Lights'. Percent germination and germ tube growth were assessed at $10,15,20,25$, and $30^{\circ} \mathrm{C}$ after $3 \mathrm{~h}$ of incubation on $1.5 \%$ water agar in the dark. Polynomial regression analyses revealed a significant effect of temperature on both germination $\left(P<0.001, R^{2}\right.$ adj $\left.=0.936\right)$ and germ tube growth $\left(P<0.001, R^{2}{ }_{\text {adj }}=0.933\right)$, with predicted optimum temperatures of 21.5 and $22.0^{\circ} \mathrm{C}$, respectively. Germination and germ tube growth were reduced greatly at $30^{\circ} \mathrm{C}$ and below $15^{\circ} \mathrm{C}$. Temperature also was found to have a significant effect on infection efficiency, as measured by incubation period $\left(P<0.001, R_{\text {adj }}^{2}=0.808\right)$ and uredinia produced $\left(P<0.001, R_{\text {adj }}^{2}=0.866\right)$. On excised leaf disks of Rhododendron 'White Lights' maintained under a 14-h photoperiod, the shortest mean incubation periods of 10.7 and 10.0 days were at 20 and $25^{\circ} \mathrm{C}$, respectively, with a predicted optimum of $23^{\circ} \mathrm{C}$. The mean incubation period at 15 and $30^{\circ} \mathrm{C}$ was approximately 4 and 3 days longer, respectively, than at the predicted optimum temperature. The number of uredinia produced was similar at 15,20 , and $25^{\circ} \mathrm{C}$, but was reduced sixfold at $30^{\circ} \mathrm{C}$. The predicted optimum temperature for uredinial production was $19.5^{\circ} \mathrm{C}$, with a $5 \%$ variation in uredinia production between 17.5 and $22^{\circ} \mathrm{C}$.
\end{abstract}

Thekopsora minima P. \& H. Sydow is a heteroecious rust, with spermogonia and aecia occurring on the needles of hemlock (Tsuga spp.) and uredinia, telia, and basidia occurring on the leaves of ericaceous plants of the genera Gaylussacia, Lyonia, Menziesia, Rhododendron, and Vaccinium (13). Deciduous azaleas (Rhododendron spp.) are one ericaceous host that increasingly is being used by the ornamental horticulture industry. Azalea hybrids, displaying a range of flower color and bloom times, now are more commercially available, making these plants more popular every year. These azaleas now are used routinely in landscape plantings, and in Vermont they often are planted within close proximity to native eastern hemlock (Tsuga canadensis (L.) Carr.). When these two hosts grow in close proximity, there is concern that incidence and severity of Thekopsora minima on Rhododendron spp. will increase.

Corresponding author: S. E. Pfister

E-mail: spfister@agr.state.vt.us

Funding and technical support of this research was provided by the Vermont Association of Professional Horticulturists, the Vermont Agency of Agriculture, Food \& Markets, and the University of Vermont, School of Environment and Natural Resources, McIntire Stennis Research Program.

Accepted for publication 30 November 2003.

Publication no. D-2004-0126-02R

(C) 2004 The American Phytopathological Society
Prior to 1993 , T. minima generally was recognized as belonging to a species complex known as Pucciniastrum vaccinii (G. Wint.) Jørst. (= P. minima (Schw.) Arth.). The confusion surrounding the species complex was clarified by Sato et al. (13), and the name $T$. minima was adopted for the eastern North American fungus. Early research in eastern North America focused on host ranges, morphology of spores and sori, and establishing the heteroecious nature of the fungus $(1,4-7,11)$. Little else is known about the biology of T. minima. Information on epidemiological factors, such as temperature, will form a basis for further studies on pathogen epidemiology, host resistance, and disease control. It was the objective of this research to determine the effect of temperature on urediniospore germination, germ tube growth, incubation period, and infection efficiency.

\section{MATERIALS AND METHODS}

Plant material. Nursery plants of the deciduous azalea cv. White Lights were obtained from Briggs Nursery (Olympia, WA) in the spring of 2000 and planted in 10-cm-diameter pots containing ProGro commercial potting mix (Scott's Co., Marysville, $\mathrm{OH}$ ) and grown outdoors for the remainder of the summer. Plants then either were replanted in $30-\mathrm{m}^{3}$ pots in the spring of 2001 or maintained within the $10-\mathrm{cm}$ pots. The azalea cv. White Lights is the result of a cross between $R$. prinophyllum (Small) Millais and an Exbury hybrid with unknown parentage. $R$. prinophyllum is native from Maine to Virginia and west to Missouri.

Production of urediniospores. Infected leaves from White Lights were collected from a previously established disease nursery in Jericho, VT. The source of the original inoculum at the nursery was from both native and nonnative Rhododendron spp. naturally infected with $T$. minima. Urediniospores were brushed off the infected leaves with a camel's hair brush into $0.1 \%$ water agar (DIFCO Bacteriological; Difco Laboratories, Detroit), suspended with the aid of a vortex, and adjusted to a concentration of $1 \times 10^{5}$ spores $/ \mathrm{ml}$ with a hemacytometer. The urediniospore mixture then was sprayed onto the abaxial leaf surface of healthy White Lights plants growing in $10-\mathrm{cm}$-diameter pots. The plants were placed in a growth chamber (S10H; Conviron Inc., Pembina, ND) and incubated in the dark at $20^{\circ} \mathrm{C}$ in a moist chamber ( $>99 \%$ relative humidity) for 24 h. The inoculated plants then were removed from the moist chamber and maintained within a growth chamber at $20^{\circ} \mathrm{C}$ under a 14-h photoperiod (6,000 Lux) for up to 3 weeks. Stocks of even-aged urediniospores were maintained by inoculating healthy plants every 2 to 3 weeks. Urediniospores used in all experiments were harvested from infected leaves 2 to 3 weeks post inoculation.

Production of leaf disks. Leaf disks were excised from healthy White Lights leaves with an 8-mm cork borer immediately prior to each experiment. Only fully mature leaves from plants growing in 30$\mathrm{m}^{3}$ pots were utilized. Leaf disks were surface disinfected in a $0.525 \%$ sodium hypochlorite solution for $1 \mathrm{~min}$, then quadruple rinsed in sterile deionized water.

Effect of temperature on germination and germ tube growth. Urediniospore germination and germ tube growth were determined at $10,15,20,25$, and $30^{\circ} \mathrm{C}$ within growth chambers (Precision/GCA Scientific Corp., Chicago). Germination slides were prepared by micropipetting $175 \mu \mathrm{l}$ of water agar (1.5\% DIFCO Bacteriological) into a concave well of a microscope slide. Immediately after the agar solidified, urediniospores suspended in $0.1 \%$ water agar $\left(1 \times 10^{5}\right.$ spores $\left./ \mathrm{ml}\right)$ were spread upon the slide agar with a sterile glass rod and placed within a humidity chamber. Humidity chambers were constructed from petri dishes 150 by $15 \mathrm{~mm}$ in diameter containing $50 \mathrm{ml}$ of water agar ( $1.5 \%$ agar) that had been placed $24 \mathrm{~h}$ previously within the growth chambers to 
allow them to adjust to the ambient temperature of each growth chamber. This procedure was repeated for 20 separate slides, with five humidity chambers each receiving four slides. After a 3-h incubation period in the dark, the slides were removed and a drop of $0.1 \%$ aniline blue in $50 \%$ lactic acid was placed on each slide to stop germination. For each slide, 10 preset fields were observed at $\times 100$ magnification and, within each field, the total number of spores and number of germinated spores were determined. A spore was considered germinated if its germ tube length was at least one-half the width of the urediniospore. The length of the germ tube nearest to the center of the microscope field also was recorded by measuring with an ocular micrometer. Spores that were not distinguishable, such as occurred with clumping, were skipped. Each incubation chamber was considered an experimental unit, and each slide a replication. There were four replications per experimental unit, with 10 subsamples per replication. The experiment was repeated and the results were pooled based upon homogeneity of variances as determined by Levene's Test (8).

Effect of temperature on uredinia development. Uredinia development was assessed on excised leaf disks by recording the mean incubation period and the number of uredinia produced. The time between inoculation and the maturation of $50 \%$ of the uredinia was considered the mean incubation period. A uredinium was considered mature if there were urediniospores visible on its surface. A $1-\mathrm{ml}$ suspension of urediniospores $\left(1 \times 10^{5} / \mathrm{ml}\right)$ was prepared as described above and pipetted onto the surface of a 100-mm-diameter water agar plate containing $20 \mathrm{ml}$ of water agar (1.5\% DIFCO Bacteriological) and the suspension was spread across the entire agar surface by gentle rotation. Sixteen 8$\mathrm{mm}$ leaf disks were placed abaxial surface down on the agar surface. The petri dish was sealed with parafilm and incubated at $20^{\circ} \mathrm{C}$ for $24 \mathrm{~h}$ in the dark. This procedure was repeated with a total of four water agar plates. After $24 \mathrm{~h}$, four leaf disks were selected randomly from each of the plates and transferred to one of four new water agar plates (16 disks/plate). They were aseptically placed abaxial surface up in rows of four. Plates then were sealed with parafilm and assigned to growth chambers (Precision/GCA Scientific Corp.) set at 15, 20,25 , and $30^{\circ} \mathrm{C}$ (one plate per chamber). Petri dishes were inverted within growth

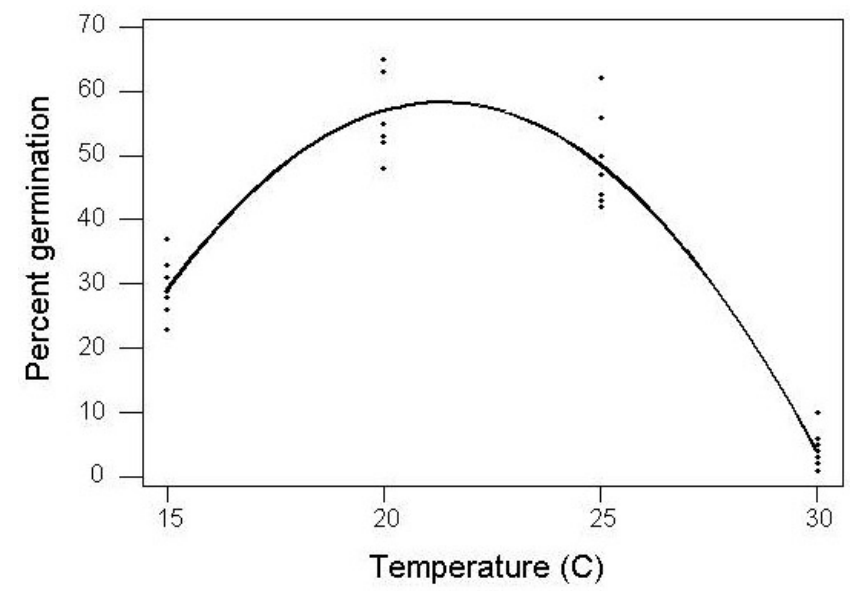

Fig. 1. Effect of temperature on percent germination of urediniospores of Thekopsora minima.

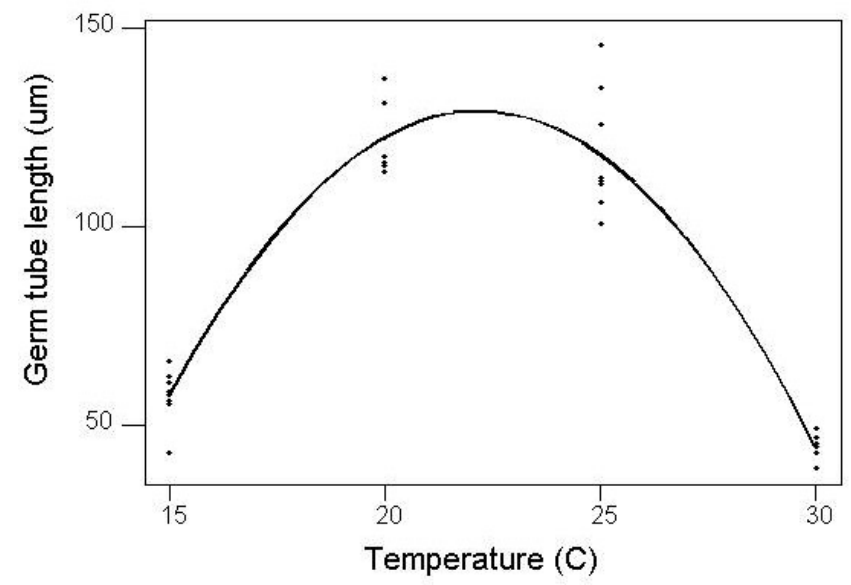

Fig. 2. Effect of temperature on Thekopsora minima urediniospore germ tube growth. chambers and maintained under a 14-h photoperiod (3,222 Lux). The inoculated leaf disks were observed daily to record the number of mature uredinia until no new mature uredinia appeared for two consecutive days. Each petri dish was considered an experimental unit, with each row of four leaf disks representing a replication. There were four replications per experimental unit, with four subsamples per replication. The experiment was repeated, and the results were pooled based upon homogeneity of variances.

Statistical analysis. Polynomial regression analyses were used to characterize stimulus-response relationships for all experiments. The Regression-Fitted Line Plot and Residual Diagnostic procedures from MINI-TAB for Windows (release 13; MiniTab Inc., State College, PA) were used for all regression analyses. The $F$ statistic $(P<$ 0.05 ) indicating a polynomial relationship between $x$ and $y$, the coefficient of determination $\left(r^{2}\right)$, the standard error $(s)$, and residual diagnostics were used to evaluate all regression models. Higher-order regression parameters not significantly different from zero $(P<0.05)$ were dropped unless higher-degree terms of the corresponding variable were associated with significant parameters (8). Predictions for percent urediniospore germination, germ tube growth, incubation period, and uredinia production were obtained from the regression equations to the nearest $0.5^{\circ} \mathrm{C}$, as well as predicted optimum temperatures for the four parameters. The 5\% variation range in response from the optimum value and the corresponding temperatures then were determined for each parameter.

\section{RESULTS}

Effect of temperature on germination and germ tube growth. After $3 \mathrm{~h}$ of incubation in the dark, no urediniospore germination occurred at $10^{\circ} \mathrm{C}$. The mean percent germination after $3 \mathrm{~h}$ was $29 \%$ at $15^{\circ} \mathrm{C}$, $57 \%$ at $20^{\circ} \mathrm{C}, 49 \%$ at $25^{\circ} \mathrm{C}$, and $4 \%$ at $30^{\circ} \mathrm{C}$. A similar relationship was found with germ tube growth. Mean germ tube growth was $58 \mu \mathrm{m}$ at $15^{\circ} \mathrm{C}, 122 \mu \mathrm{m}$ at $20^{\circ} \mathrm{C}, 118 \mu \mathrm{m}$ at $25^{\circ} \mathrm{C}$, and $45 \mu \mathrm{m}$ at $30^{\circ} \mathrm{C}$. The germination rate was nearly halved at $15^{\circ} \mathrm{C}$, and this effect was even more pronounced with germ tube growth. Higher temperatures had an even more pronounced effect upon germination. There was a marked decrease in germination above $25^{\circ} \mathrm{C}$, with the rate declining by approximately $9 \%$ for every increase in $1^{\circ} \mathrm{C}$ (Fig. 1). The impact upon germ tube growth was not as severe at higher temperatures. Once germination took place, the rate of growth was only 2.5 times greater at 25 than at $30^{\circ} \mathrm{C}$.

No germination occurred at $10^{\circ} \mathrm{C}$; therefore, data from this temperature were not factored into regression analyses. The relationship between temperature and percent germination was described by the quad- 
ratic equation $y=-270.925+30.8425 T-$ $0.7225 T^{2}\left(s=5.4, R_{\text {adj }}^{2}=0.936, P<\right.$ 0.001 ), where $y=$ percent germination and $T=$ temperature $\left({ }^{\circ} \mathrm{C}\right)$, with $21.5^{\circ} \mathrm{C}$ being the predicted optimum temperature for urediniospore germination (Fig. 1). The predicted optimum temperature for germ tube growth was $22^{\circ} \mathrm{C}$, as determined by the relationship between germ tube growth and temperature, which was described by the quadratic equation $y=$ $-553.210+61.4903 T-1.38548 T^{2}(s=$ $\left.9.5, R_{\text {adj }}^{2}=0.933, P<0.001\right)$, where $y=$ germ tube growth $(\mu \mathrm{m})$ and $T=$ temperature $\left({ }^{\circ} \mathrm{C}\right.$ ) (Fig. 2). Whereas the predicted optimum temperatures for urediniospore germination and germ tube growth were 21.5 and $22^{\circ} \mathrm{C}$, respectively, the ranges of 19 to $23^{\circ} \mathrm{C}$ and 20 to $24^{\circ} \mathrm{C}$, respectively, could be considered favorable as well. Within these temperature ranges, there was only an approximate 5\% variation in percent germination and germ tube growth (Table 1).

Effect of temperature on uredinia development. The mean incubation period was found to be 14.1, 10.7, 10.0, and 12.9 days post inoculation at $15,20,25$, and $30^{\circ} \mathrm{C}$, respectively. The relationship between temperature and incubation period was described by the equation $y=43.7219$ $-2.92063 T+0.063125 T^{2}\left(s=0.8, R_{\text {adj }}^{2}=\right.$ $0.808, P<0.001)$, where $y=$ incubation period (days) and $T=$ temperature $\left({ }^{\circ} \mathrm{C}\right)$ (Fig. 3). The predicted optimum temperature for $50 \%$ uredinia development $(9.9$ days) was $23^{\circ} \mathrm{C}$; however, from 20 to $26^{\circ} \mathrm{C}$ ( $5 \%$ variation), the incubation period varied by only approximately half of a day (Table 1, Fig. 3). Temperatures above and below this range resulted in a protracted incubation period. The mean incubation period was approximately 4 and 3 days longer than the predicted optimum at 15 and $30^{\circ} \mathrm{C}$, respectively. It should be noted that residual analysis indicated an increasing variance with an increasing $y$ value, causing concern over variance homogeneity. Therefore, weighted least squares regression analysis also was conducted, and a significant difference $(P<0.001)$ was found between the dependent variable, incubation period, and the independent variable, temperature.

Infection efficiency, as expressed by the number of uredinia, was nearly six times greater at 15 to $25^{\circ} \mathrm{C}$ than at $30^{\circ} \mathrm{C}$. The mean number of uredinia produced per 8mm leaf disk was $27.3,32.3$, and 26.2 at 15 , 20, and $25^{\circ} \mathrm{C}$, respectively, but declined rapidly to 4.7 uredinia at $30^{\circ} \mathrm{C}$. The relationship of number of uredinia and the effect of temperature can be described by the quadratic equation $y=-70.0278+$ $10.4536 T-0.265187 T^{2}\left(s=4.2, R_{\text {adj }}^{2}=\right.$ $0.866, P<0.001)$, where $y=$ number of uredinia and $T=$ temperature $\left({ }^{\circ} \mathrm{C}\right)$ (Fig. 4). The predicted optimum temperature for uredinia production was $19.5^{\circ} \mathrm{C}$, with a $5 \%$ variation of 17.5 to $22^{\circ} \mathrm{C}$ (Table 1, Fig. 4).

\section{DISCUSSION}

Urediniospores of T. minima germinate rapidly at optimum temperatures varying from 19 to $23^{\circ} \mathrm{C}$. A 3-h incubation time was chosen to best show a separation of germination rates under the test temperatures; however, germination of urediniospores did not occur at $10^{\circ} \mathrm{C}$ within $3 \mathrm{~h}$. In preliminary experiments, germination at $10^{\circ} \mathrm{C}$ did occur at a reduced rate with a longer incubation period of $5 \mathrm{~h}$, but difficulty was encountered when measuring germ tube length at optimal temperatures. The optimum temperature range for $T$. minima urediniospore germination is similar to ranges reported for other rust pathogens $(3,9,14)$.

Table 1. Predicted optimum temperature and 5\% variation range for urediniospore percent germination, germ tube growth, incubation period, and uredinia production for Thekopsora minima

\begin{tabular}{lcc}
\hline Variables & Predicted optimum $\left({ }^{\circ} \mathbf{C}\right)$ & Range $^{\mathbf{a}}$ \\
\hline Percent germination & 21.5 & $19.0-23.0$ \\
Germ tube growth $(\mu \mathrm{m})$ & 22.0 & $20.0-24.0$ \\
Incubation period $($ days $)$ & 23.0 & $20.0-26.0$ \\
Uredinia production & 19.5 & $17.5-22.0$ \\
\hline
\end{tabular}

${ }^{a}$ The 5\% variation range is defined as the temperature range in which there is a $5 \%$ variation in response from the predicted optimum temperature.

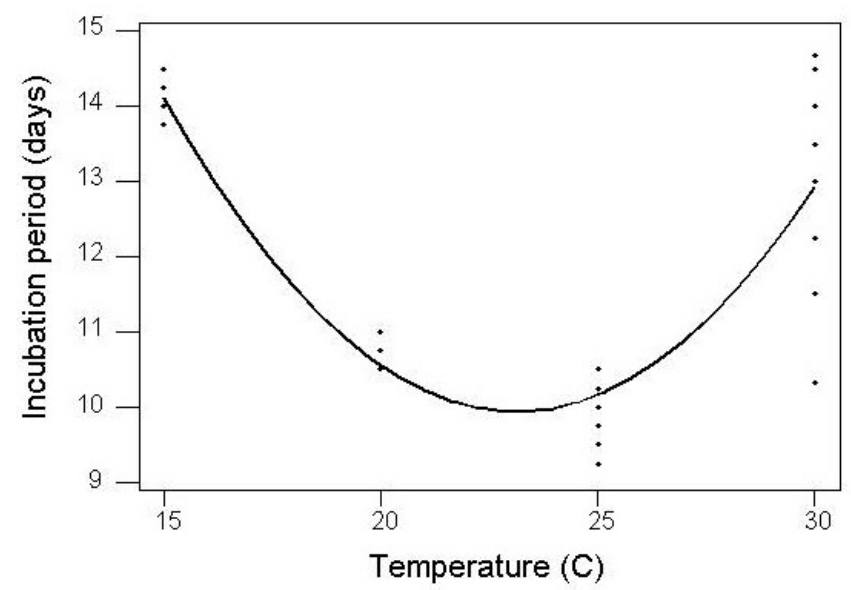

Fig. 3. Effect of temperature on incubation period of Thekopsora minima urediniospores on Rhododendron 'White Lights'.

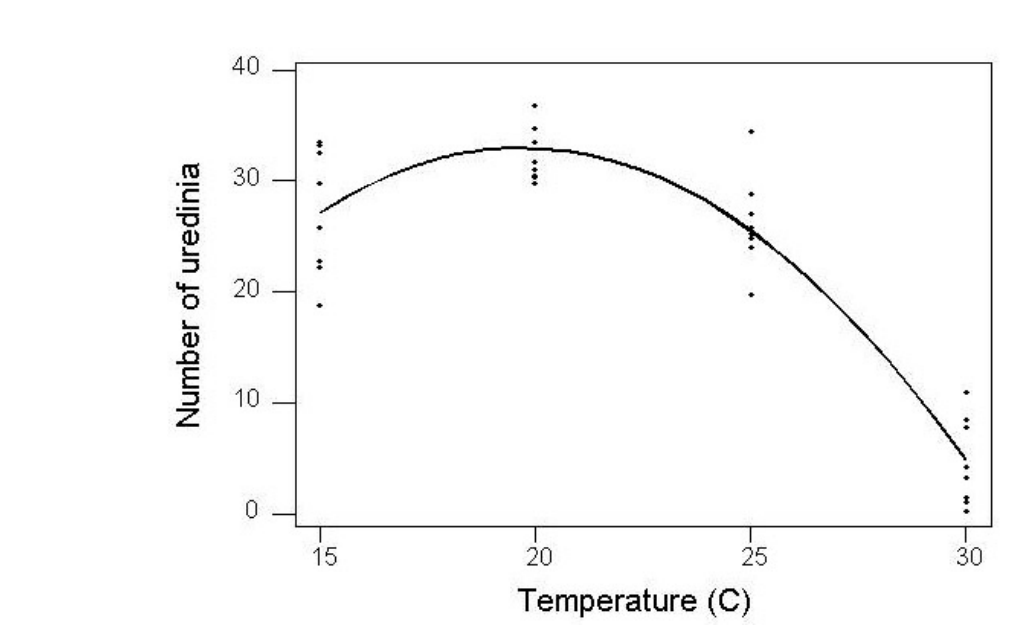

Fig. 4. Effect of temperature on number of uredinia produced by Thekopsora minima urediniospores

on excised leaf disks of Rhododendron 'White Lights'.
In our study with T. minima, the shortest opment of $50 \%$ mature uredinia occurred at $23^{\circ} \mathrm{C}$. The incubation period increased at temperatures above and below this temperis $\left(21.5^{\circ} \mathrm{C}\right)$ and germ tube growth $\left(22^{\circ} \mathrm{C}\right)$, but it is $3.5^{\circ} \mathrm{C}$ higher than the optimum for uredinial production $\left(19.5^{\circ} \mathrm{C}\right)$. This sevfor uredinial production compared with the optima for germination, germ tube growth, and incubation period is not unprecedented. Mendes and Bergamin (10) found that Uromyces phaseoli var. typica infection of bean had the shortest incuba- 
tion period at $21^{\circ} \mathrm{C}$; however, the greatest amount of uredinia occurred at $17^{\circ} \mathrm{C}$. Mendes and Bergamin theorized that this contrast in optimum temperatures could be explained by the compensation phenomenon proposed by Rotem (12) and expanded on by Aust et al. (2). The authors proposed four compensation categories that allow pathogens the ability to cause epidemics under differing environmental conditions. One of the categories, phase-to-phase compensation, is defined by Rotem as "a high frequency of occurrence of one phase of the life cycle of a pathogen that can compensate for a low frequency of occurrence of another phase in the life cycle of the pathogen". This is illustrated in Mendes and Bergamin's study, where temperature affects two phases of the life cycle of the pathogen differently: incubation period and disease efficiency. Longer incubation periods occur for bean rust with temperatures lower than $21^{\circ} \mathrm{C}$, but this is compensated for with considerably higher disease efficiency. This $4^{\circ} \mathrm{C}$ temperature difference between incubation period and uredinia production in bean rust is similar to the results being reported here for T. minima, which had a predicted optimum of $23^{\circ} \mathrm{C}$ for incubation period and $19.5^{\circ} \mathrm{C}$ for uredinia production. This suggests that a phase- to-phase compensation phenomenon occurs with T. minima.

The use of polynomial regression analyses worked well to characterize the stimulus-response relationships for all experiments. Utilizing the Rhododendron cv. White Lights and a population of T. minima native to Vermont, an overlap in the predicted optimum temperature $5 \%$ variation ranges for germination, germ tube growth, incubation period, and uredinia production occurred from 20 to $22^{\circ} \mathrm{C}$. Further research is needed to determine if the optimal temperature range found within our study is consistent for populations of $T$. minima and other ericaceous hosts over a range of elevations and latitudes.

\section{LITERATURE CITED}

1. Adams, J. F. 1919. Rusts on conifers in Pennsylvania. Bull. Penn. State Coll. Agric. Exp. Stn. 160:3-30.

2. Aust, H. J., Bashi, E., and Rotem, J. 1980. Flexibility of plant pathogens in exploiting ecological and biotic conditions in the development of epidemics. Pages 45-56 in: Comparative Epidemiology. J. Palti and J. Kranz, eds. Pudoc, Wageningen, the Netherlands.

3. Butler, D. R., and Jadhav, D. R. 1991. Requirements of leaf wetness and temperature for infection of groundnut by rust. Plant Pathol. 40:395-400.

4. Clinton, G. P. 1911. Notes on plant diseases of
Connecticut. Conn. Agric. Exp. Stn. Annu. Rep. 33 \& 34:713-738.

5. Fraser, W. P. 1912. Cultures of heteroecious rusts. Mycologia 4:175-193.

6. Fraser, W. P. 1913. Further cultures of heteroecious rusts. Mycologia 5:233-239.

7. Fraser, W. P. 1914. Notes on Uredinopsis mirabilis and other rusts. Mycologia 6:25-28.

8. Kleinbaum, D. G., Kupper, L. L., Muller, K. E., and Nizam, A. 1998. Applied Regression Analysis and Other Multivariable Methods. Duxbury Press, Pacific Grove, CA.

9. Malliah, K. V., and Rao, A. S. 1979. Groundnut rust: Factors influencing disease development, sporulation and germination of uredospores. Indian Phytopathol. 32:382-388.

10. Mendes, B. M. J., and Bergamin Filho, A. 1988. Influence of temperature, wetness duration and leaf type on the quantification of monocyclic parameters of bean rust. J. Phytopathol. 126:183-189.

11. Pady, S. M. 1933. Teliospore development in the Pucciniastreae. Can. J. Res. 9:458-485.

12. Rotem, J. 1978. Climatic and weather influences on epidemics. Pages 317-337 in: Plant Disease, an Advanced Treatise. Vol. II. J. G. Horsfall and E. B. Cowling, eds. Academic Press, New York.

13. Sato, S., Katsuya, K., and Hiratsuka, Y. 1993. Morphology, taxonomy and nomenclature of Tsuga-Ericaceae rusts. Trans. Mycol. Soc. Jpn. 34:47-62.

14. Tapsoba, H., and Wilson, J. P. 1997. Effect of temperature and light on germination of urediniospores of the pearl millet rust pathogen, Puccinia substriata var. indica. Plant Dis. 81:1049-1052. 